\title{
Accidental Drop of a Carbon Steel/Lead Shipping Cask at Low Temperatures
}

\section{ASME Pressure Vessels and Piping Division Conference}

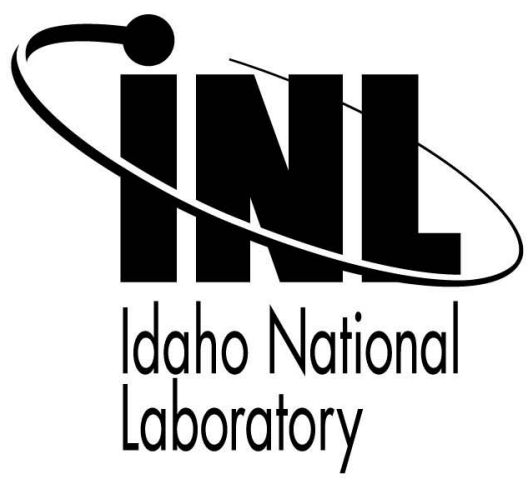

Brian D. Hawkes

Kenneth R. Durstine

July 2007

This is a preprint of a paper intended for publication in a journal or proceedings. Since changes may be made before publication, this preprint should not be cited or reproduced without permission of the author. This document was prepared as an account of work sponsored by an agency of the United States Government. Neither the United States Government nor any agency thereof, or any of their employees, makes any warranty, expressed or implied, or assumes any legal liability or responsibility for any third party's use, or the results of such use, of any information, apparatus, product or process disclosed in this report, or represents that its use by such third party would not infringe privately owned rights. The views expressed in this paper are not necessarily those of the United States Government or the sponsoring agency. 
Proceedings of PVP2007 / CREEP 8

2007 ASME Pressure Vessels and Piping Division Conference

July 22-26, 2007, San Antonio, TX

PVP200726371

\title{
ACCIDENTAL DROP OF A CARBON STEEL/LEAD SHIPPING CASK AT LOW TEMPERATURES ${ }^{1}$
}

\author{
Brian D. Hawkes \\ Kenneth R. Durstine \\ Idaho National Laboratory \\ P.O. Box 1625 \\ Idaho Falls, Idaho 83415-3760 \\ United States of America \\ (208) 526-2870, (208) 533-7471, Brian.Hawkes@inl.gov
}

\section{ABSTRACT}

A shielded cask is used to transport radioactive materials between facilities. The cask was fabricated with an outer and inner shell of hot rolled low carbon steel. Lead was poured in the annular space between the shells to provide radiation shielding. Carbon steel is known to be susceptible to lowtemperature brittle fracture under impact loading. This paper will present the analysis results representing postulated transportation accidents during on-site transfers of the cask. The accident scenarios were based on a series of cask drops onto a rigid surface from a height of $6 \mathrm{ft}$ assuming brittle failure of the cask shell at subzero temperatures.

Finite element models of the cask and its contents were solved and post processed using ABAQUS software. Each model was examined for failure to contain radioactive materials and/or significant loss of radiation shielding.

Results of these analyses show that the body of the cask exhibits considerable ruggedness and will remain largely intact after the impact. There will be deformation of the main cask body with localized brittle failure of the cask outer shell and components and but no complete penetration of the cask shielding. The cask payload outer waste can will experience some permanent plastic deformation in each drop, but will not be deformed to the point where it will rupture, thus maintaining confinement of the can contents.

\section{INTRODUCTION}

The Materials and Fuels Complex (MFC), located at the Idaho National Laboratory (INL), uses a shielded cask for intrasite transport of radioactive materials between buildings inside the facility. The facilities operate year around, dictating that some transfers take place in the cold Idaho winter. For safety reasons, transfers do not normally occur during extreme cold weather; however, an equipment failure could leave the cask exposed to subzero temperatures. Major components of the cask were fabricated using carbon steel, which is known to be susceptible to brittle fracture under impact loading at low temperatures. This paper demonstrates that brittle fracture resulting from a transportation accident will not prevent the cask from performing its necessary functions of providing radiation shielding to nearby personnel and confinement of the radioactive payload inside the outer waste can.

The cask is essentially two concentric cylinders with a center chamber for the payload (see Fig. 1). See Table 1 for cask dimensions and weight. The outer and inner shells were fabricated from hot rolled low carbon steel with lead poured into the annular space between the steel shells to provide radiation shielding. Loading and unloading of the cask is accomplished using sliding doors at the top and bottom of the cask.

\footnotetext{
${ }^{1}$ Work supported by the U. S. Department of Energy, Office of Nuclear Energy under DOE Idaho Operations Office Contract No. DE-AC0705 ID14517.
} 


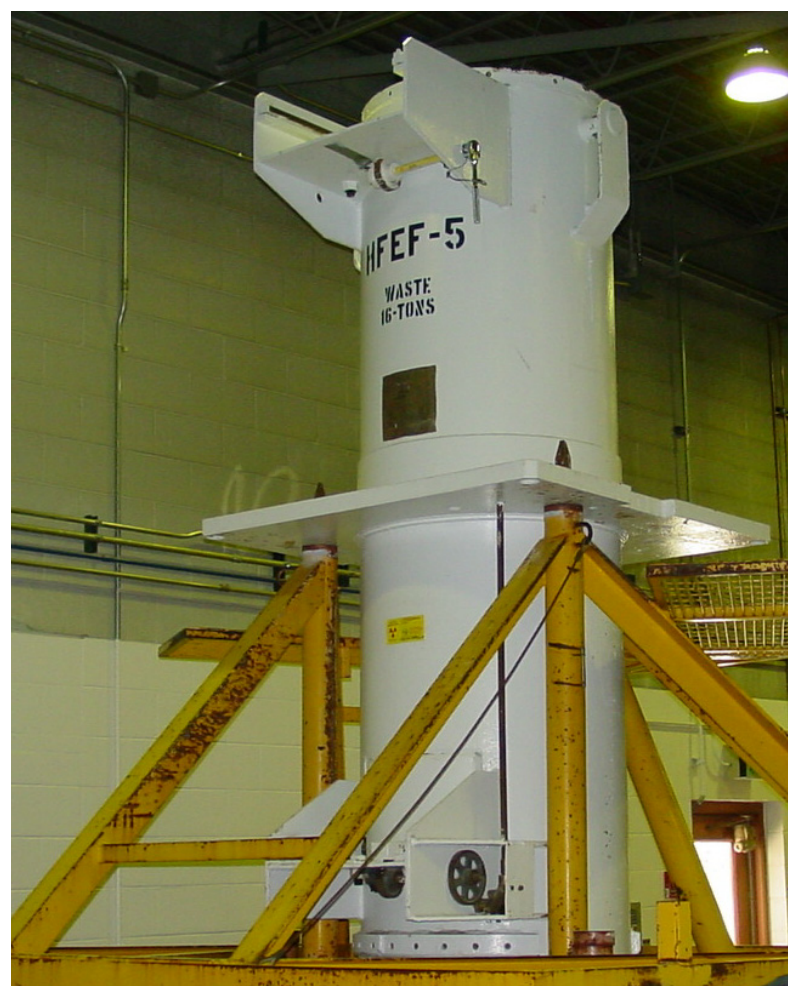

Figure 1. Shipping cask.

The doors (Fig. 2) are approximately nine inches thick, twenty inches wide and twenty two in. long and are the same plate steel/lead construction as the cask. The doors travel on rollers with hand cranked rack and pinion gears to open and close them. Two 1-1/8 in. diameter grade eight bolts pass through the front lip of the doors and into the support structure below the doors to prevent opening during transit. The cask has a two in. thick, fifty two inch square support plate about midway up the cask. This support plate has three holes matching the pins on the forklift $\mathrm{C}$-frame fixture to keep the cask mounted on the forklift during transit.

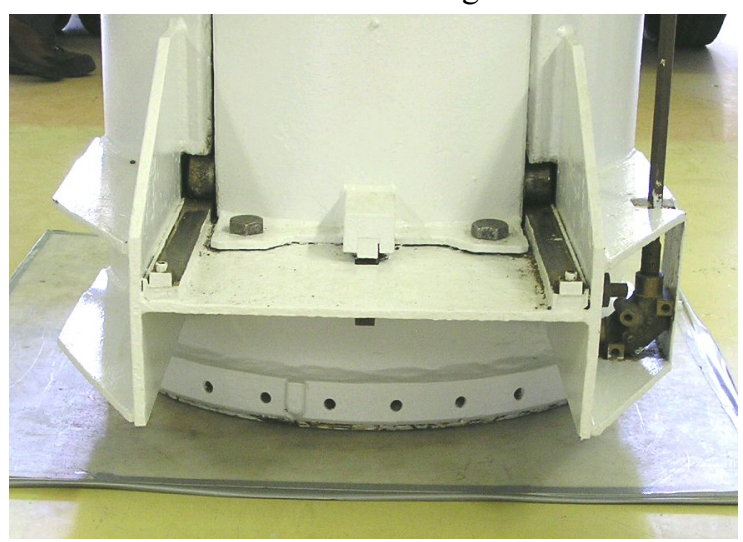

Figure 2. View of lower door showing bolts and support structure.
Table 1. Cask Parameters

\begin{tabular}{|l|l|}
\hline Cask Dimension/Weight & Value \\
\hline \hline Outside Diameter & $32-3 / 4$ in. \\
\hline Inner Diameter & $14-1 / 2$ in. \\
\hline Height & $106-5 / 8$ in. \\
\hline Gross Weight & $32,000 \mathrm{lbf}$ \\
\hline Outer shell thickness & $3 / 8 \mathrm{in}$. \\
\hline Inner shell thickness & $1 / 4 \mathrm{in}$. \\
\hline $\begin{array}{l}\text { Steel plate thickness (unless } \\
\text { otherwise specified) }\end{array}$ & $3 / 8$ in. \\
\hline Typical Lead Infill Thickness & $8-1 / 2$ in. \\
\hline
\end{tabular}

The cask payload is carried in the center chamber in containers nested inside a 304 stainless steel outer waste can (outer can). The confinement function of the cask is provided by the outer waste can although the inner containers also provide containment.

Table 2. Waste Can Parameters

\begin{tabular}{|l|l|}
\hline Can Dimension/Weight & Value \\
\hline Outside Diameter & $12-3 / 4$ in. \\
\hline Wall thickness & 0.078 in. (14 ga.) \\
\hline Height & $73-3 / 8$ in. \\
\hline End plate thickness & $1 / 4 \mathrm{in.}$ \\
\hline Gross weight & $1500 \mathrm{lbf}$ \\
\hline
\end{tabular}

MATERIAL CONSIDERATIONS

The drawings specify that the cask was fabricated from low carbon hot rolled steel. No further specifications were listed for this material. Therefore it is assumed that the steel is a plain low carbon steel with carbon content between $0.05 \%$ and $0.30 \%$. Plain carbon and low alloy steels typically have body centered cubic (BCC) lattice structures. BCC are known to lose impact resistance with decreasing temperatures and have increased risk of brittle failure [1]. Charts of the transition temperature of steel as a function of carbon content indicate the brittle-ductile transition temperature for $0.11 \%$ carbon content plain steel is the range of $-50^{\circ} \mathrm{F}$, approximately $0^{\circ} \mathrm{F}$ for $0.20 \%$ carbon and a gradual transition occurring over a range of 0 to $200^{\circ} \mathrm{F}$ for $0.31 \%$ carbon. Flynn [2] indicates the transition temperature could be much lower. Without a sample of the material, and in the time available, the ductilebrittle transition temperature could not be exactly determined. Therefore the material was conservatively modeled as elastic at small strains (up to the yield point) and then assumed to fail by brittle fracture. Material properties are listed in Table 3.

Lead and austenitic stainless steel are characterized as having a face centered cubic (FCC) lattice structures. They do not suffer from a loss of impact strength at the low 
temperatures being considered and are considered ductile. The heat generated by the radioactive payload will warm the inner carbon steel shell of the cask and therefore it may also be considered ductile.

Table 3. Material Properties

\begin{tabular}{|l|c|l|}
\hline Material & $\begin{array}{l}\text { Yield Strength } \\
\text { (ksi) }\end{array}$ & $\begin{array}{l}\text { Modulus of } \\
\text { Elasticity } \mathbf{( 1 0}^{\mathbf{6}} \\
\text { psi) }\end{array}$ \\
\hline Low carbon steel & 42.0 & 29.0 \\
\hline Lead & 2.5 & 2.0 \\
\hline 304 Stainless steel & 30.0 & 28.3 \\
\hline
\end{tabular}

\section{ACCIDENT SCENARIOS}

The cask is transferred at speeds of $10 \mathrm{mph}$ or less, using a large 20 ton forklift with a $\mathrm{C}$-frame to raise the cask clear of the ground. Operating procedures keep the center of gravity $(\mathrm{cg})$ of the cask within six feet of the surface. The travel path of the cask traverses asphalt pavement, rock and gravel roadways, compacted soil, and the concrete aprons in the immediate vicinity of the facility buildings.

The accident scenarios assume that the cask will fall from a height of six feet and impact on concrete. Three orientations were selected to represent the impacts that would most severely damage the cask components or the payload in the waste can.

1. Cask in a vertical orientation impacting on the flat bottom.

2. Cask in a tilted orientation impacting on a bottom edge with the cask cg over the impacting bottom corner.

3. Cask in a horizontal orientation impacting on its side.

If the cask is dropped, the horizontal velocity will cause the cask to skid along the concrete, asphalt or gravel. The horizontal deceleration would be small compared to the vertical deceleration arising from the impact. This would not be true if the cask was dropped near a massive structure that would act as a rigid body and rapidly decelerate the cask horizontally. This is not a plausible event considering how the cask is transported and the facility layout. As damage arising from the decelerations from $10 \mathrm{mph}$ horizontal velocity is expected to be relatively minor, they need not be included in the analysis.

None of the accident scenarios examine how well the cask resists penetration. Although not required by site conditions, a 40-in side drop onto a 6-in. diameter rigid pin [3] at an unreinforced location on the cask was added.
The cask must provide two functions to satisfactorily survive these events. (1) Since the shielded cask itself is not sealed, the outer waste can must undergo the impact without tearing or breaching in order to ensure that radioactive contents do not escape to the environment. (2) The cask must also maintain its gross geometry well enough to provide adequate shielding to nearby personnel and keep the waste can captive inside the cask.

\section{FINITE ELEMENT MODEL}

A finite element model was created of the cask in IDEAS 12 NX [4] and translated into an ABAQUS/Explicit [5] input file.

The cask was modeled using brick elements for the lead and then coated with shell elements for the inner and outer low carbon steel shell elements. Typical element length is about 1.25 in. (Fig. 3). The doors were modeled using the same method. The density of the lead was increased to bring the total weight of the cask (including the outer can) to 16 tons. It was also assumed that the lead and steel plates were bonded. This assumption simplified the creation and of the finite element model and reduced the solution time. This simplification was judged to have a small influence in the outcome of the analysis because the damaged shell elements will be removed from the analysis when it would begin to make a difference whether they were bonded or not.

The outer can was modeled with thin shell elements with their density increased to account for the weight of the contents. This is conservative in that the stiffness of the contents does not add to the strength of the outer can. Also, all the energy will be absorbed by the can and not the contents. However, larger than actual deformation of the outer can is expected when using this technique.

The rack and pinion system used to operate the doors was not included in the finite element model.

Failure of the outer layer of carbon steel was defined in the ABAQUS/Explicit model as tensile failure for brittle materials. The cutoff stress was defined as $\sigma_{y} / 3$ per the discussion in the ABAQUS Theory Manual for Isotropic Elasto-Plasticity material definition. This failure theory (tensile failure) assumes failure when the pressure stress component is higher than the cutoff stress. This means that there is no plastic behavior in this material and when the cutoff stress is used, failure occurs when $\sigma_{y}$ is reached. This model was chosen because it more closely represents the brittle behavior of the outer steel shell.

Welds were included in the model where the baseplate is attached to the cask and also where the lifting plate is welded to the cask. These welds are modeled with thin shell elements with the shell thickness equal to the fillet weld throat length.

The 1-1/8 in. door bolts were modeled as circular beams with a radius of 0.4928 inches, which is the radius of the thread stress area. These beam elements were monitored during the analysis to determine whether or not failure occurred. 
ABAQUS/Explicit general contact was used to simplify the contact for this analysis.

The finite element model was impacted on a rigid surface with an initial velocity to simulate a drop onto a concrete pad from a height of $6 \mathrm{ft}$.

\section{ANALYSIS RESULTS}

\section{Flat bottom}

The flat bottom drop configuration is shown in Fig. 3 . Results of this drop show that some of the outer carbon steel shell, door support structure, and the bottom plate elements will fail and were removed from the model (Fig. 4). The maximum displacement of the lead was $0.415 \mathrm{in}$. The outer can has a maximum strain of $5.2 \%$, which is much less than the allowable of $40 \%$ [6] and does not rupture. The outer waste can becomes about 0.394 in. shorter and 0.288 in. wider. The bolts do not fail in this drop. The displacements of various nodes tracked during the impact of the cask are shown in Fig. 5.

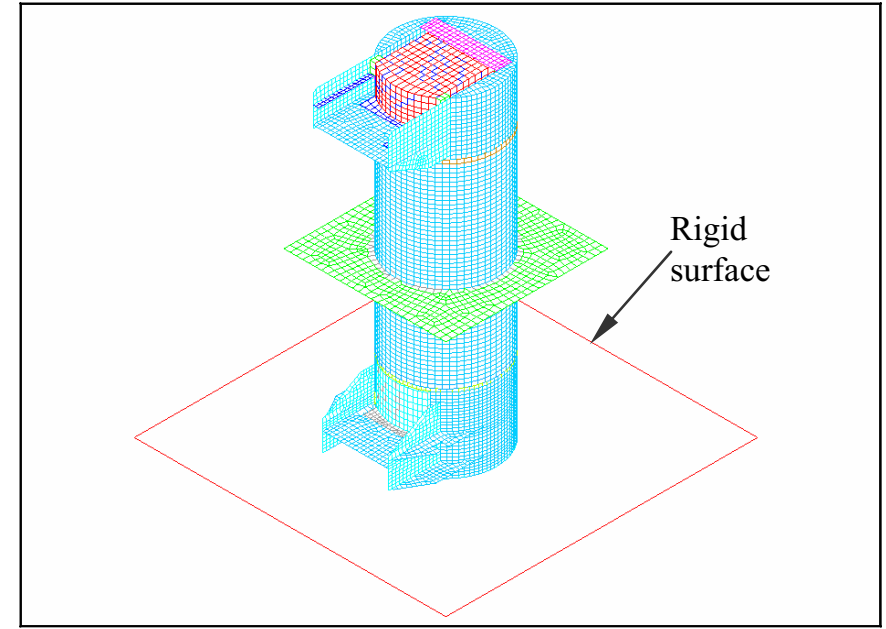

Figure 3. Finite element model of the flat bottom drop.

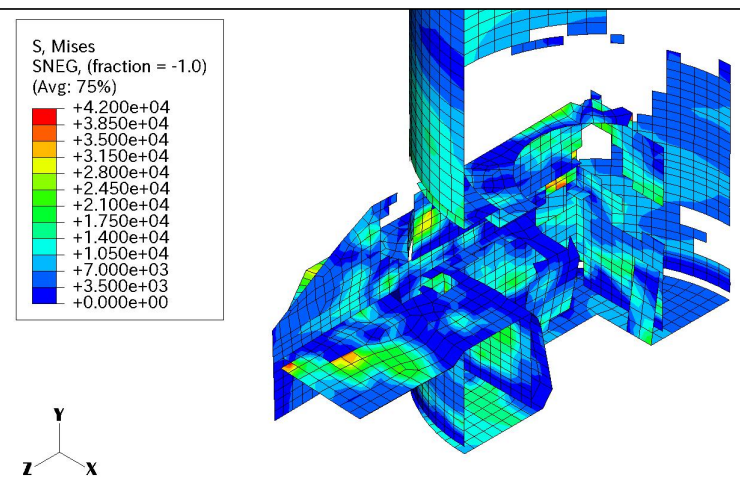

Figure 4. Cutaway view showing the outer carbon steel elements removed during the analysis at 10 milliseconds.

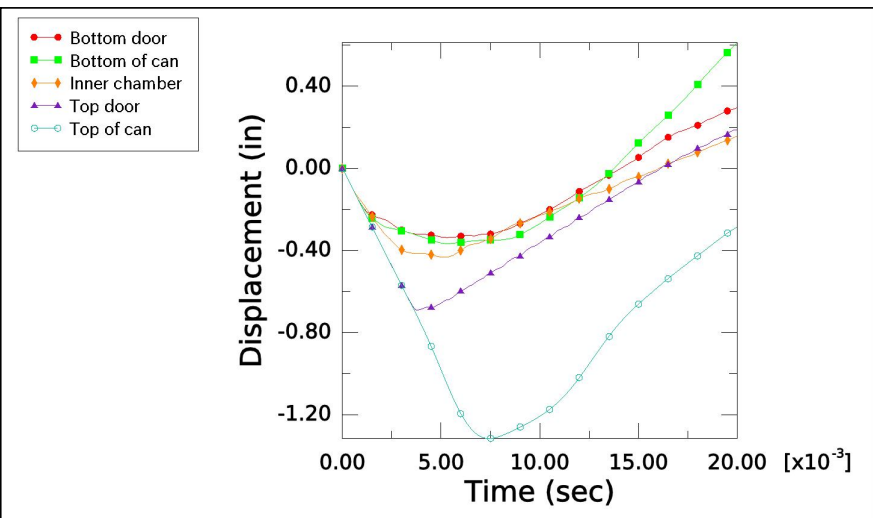

Figure 5. Vertical displacement of various nodes in the model.

\section{Front Bottom Corner}

The cask was tilted in an orientation to impact on the front bottom edge with the cask cg over the impacting bottom corner and perpendicular to the rigid surface. Figure 6 shows a cutaway view of the cask (without lead) during the front bottom corner drop. The elements that have failed are local to the impact region and have been removed during the analysis. It is seen that the bottom door is still in place and offers shielding, but the door support structure has generally failed. This allows the door bolts to go free which would allow the door to open if the structure was not distorted in the impact. The maximum deformation of the bottom corner of the cask is less than two inches (Fig. 7). The maximum strain in the outer can is $1.8 \%$. Displacement of the specified nodes is shown in Fig. 8.

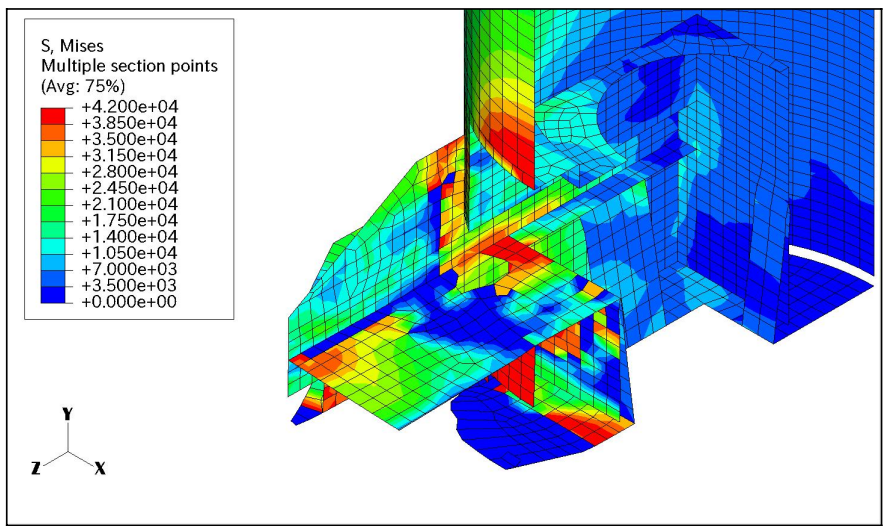

Figure 6. Cutaway view showing the front bottom corner drop showing elements that have not failed. 


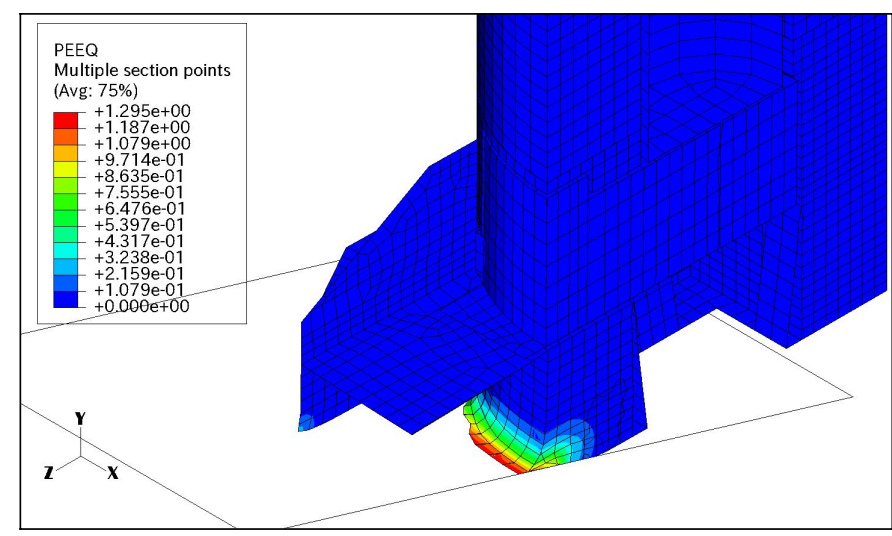

Figure 7. Cutaway view showing undamaged steel and lead elements. Maximum deformation is less than 2.0 inches

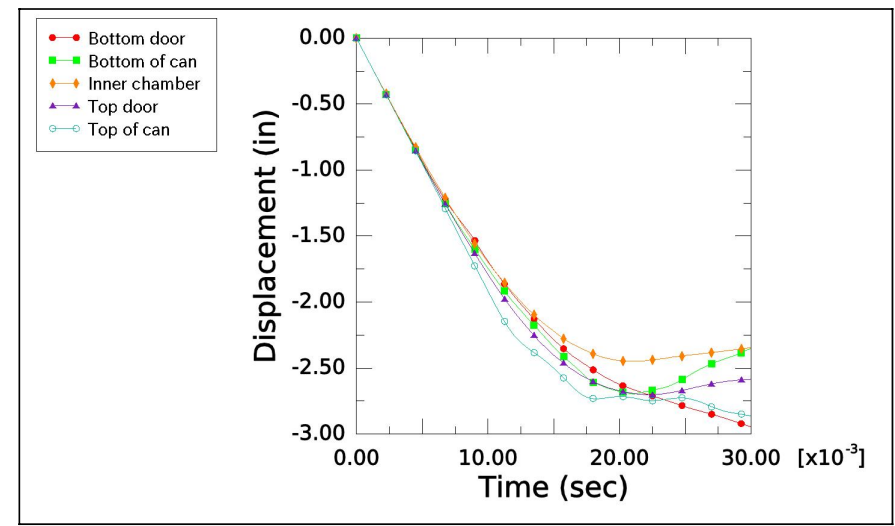

Figure 8. Displacement of various nodes in the model.

\section{Side Drop}

The cask was dropped horizontally on its side, perpendicular to the door support structures. A horizontal front drop would cause the door support structures to deform which would not allow the doors to open, but the door support structures would also absorb some energy and prolong the period of the impact. This would result in less deceleration than a side impact which would provide higher deceleration.

The first structure to impact the rigid surface will be the 2 in.-thick support plate in the middle of the cask (Fig. 9). This plate will transfer the forces to the outer shell elements and subsequently to the underlying lead elements (Fig. 10). The maximum strain in the lead is $13 \%$ and the maximum strain in the outer can is about 3\%. The maximum displacement of the lead is about $0.5 \mathrm{in}$. Displacements of the specified nodes are shown in Fig. 11. The door bolts do not fail during this drop.

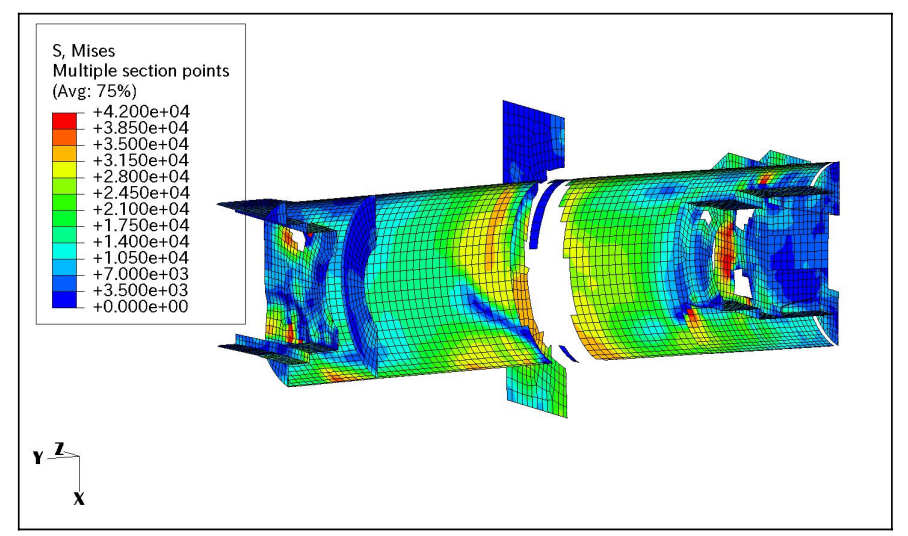

Figure 9. Cutaway view of the cask at 10 milliseconds showing the undamaged outer steel and weld elements

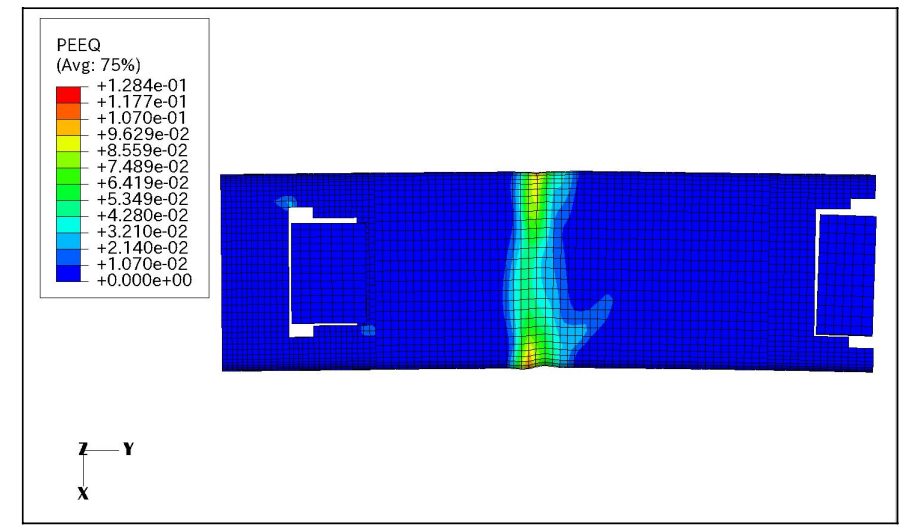

Figure 10. Plastic strains in the lead under the lifting plate are about $13 \%$. Note the bowing of the cask.

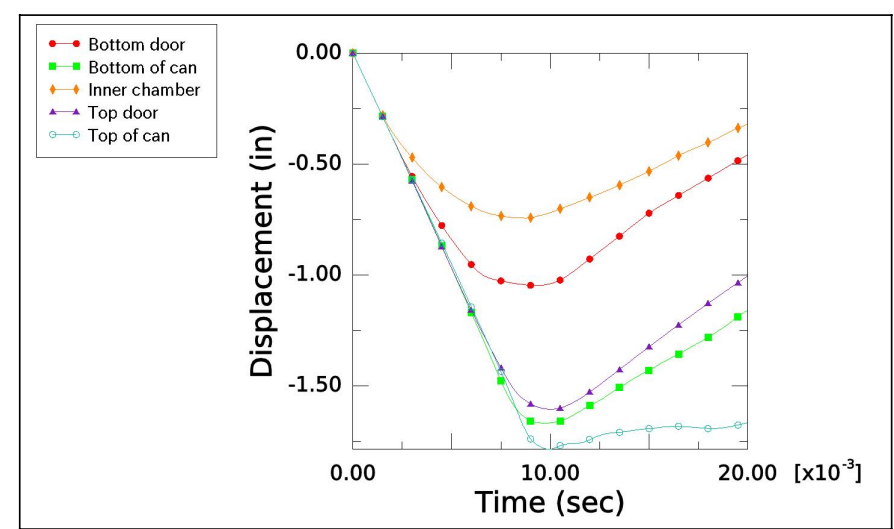

Figure 11. Displacement of the specified nodes.

\section{Front Post Drop}

This drop shows the results of dropping the cask 40 inches onto a 6 -inch diameter rigid post. The post impacts the front of the cask just below the $3 / 8$-in. thick reinforcing belt near the lifting plate. Although not required by site conditions, this drop is used to demonstrate the puncture resistance of the cask. Results of this drop are shown in Fig. 12. The cask is indented 3.36 in. on the outside and bulges upward 1.29 in. in the interior of the cask. The lead is 2.12 in. thinner in the vicinity of the post impact. The outer can is 
indented 1.32 in. (Fig. 13). Displacements of the specified nodes are shown in Fig. 14. The bolts do not fail during this drop and the doors stay in place.

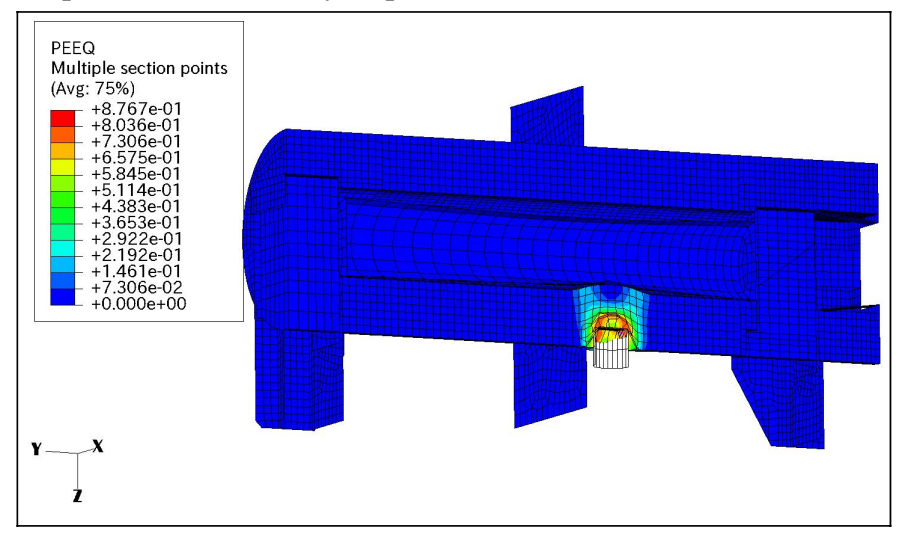

Figure 12. View of the cask drop on a rigid post. All elements are displayed.

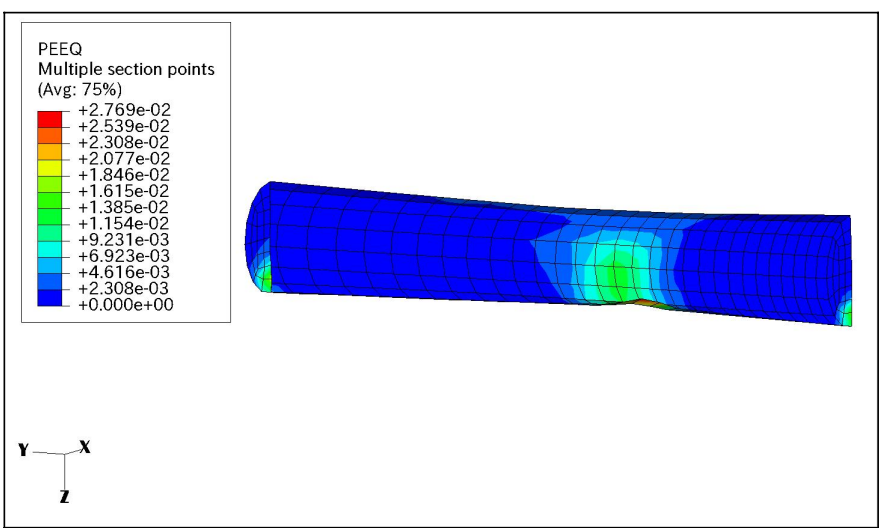

Figure 13. Cutaway view showing plastic strain and deformation in the outer can.

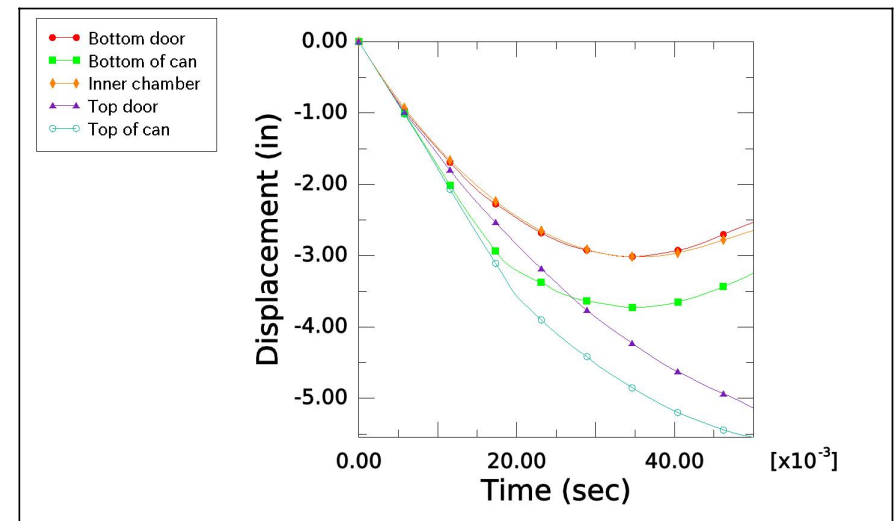

Figure 14. Displacement of the specified nodes.

\section{CONCLUSION}

This series of impact analyses show the results of dropping the cask during low-temperature operating conditions in different orientations. The body of the cask exhibits considerable ruggedness and will remain largely intact after the impact. There will be localized failure of the door support structures and deformation of the main cask body but no complete breach of the cask body lead shielding.

This drop analysis shows that:

1. The outer waste can will experience some permanent plastic deformation in each drop, but will not be deformed to the point where it will rupture. The can will maintain confinement of its contents.

2. The post impact will cause the most lead thinning. In the region of the impact the lead will become approximately 2.12 inches thinner. The bottom corner drops will decrease the thickness of the lead in the vicinity of the impact, but this lead acts as secondary shielding while the bottom door lead acts as the primary shielding.

3. The doors stay in place except for the front bottom drop where the door support structure fails. In this event, the shield doors may open far enough to partially expose the cask interior payload to the environment. However, the distortion of the remaining door support structures and the remains of the rack and pinion drive make it unlikely that neither door will completely escape its mounting which will keep the outer waste can contained within the body of the cask.

\section{ACKNOWLEDGMENTS}

This paper was prepared as an account of work sponsored by an agency of the U. S. Government. Neither the U. S. Government nor any agency thereof, or any of their employees, makes any warranty, expressed or implied, or assumes any legal liability or responsibility for any third party's use, or the results of such use, of any information, apparatus, product or process disclosed in this report, or represents that its use by such third party would not infringe privately owned rights. The views expressed in this paper are not necessarily those of the U.S. DOE.

\section{REFERENCES}

[1] Taylor, L., 1961, "Metals Handbook", $8^{\text {th }}$ Edition, American Society for Metals, Metals Park, Ohio.

[2] Flynn, T. M., 1997, “Cryogenic Engineering”, Marcel Dekker, Inc., New York, New York.

[3] 10 CFR Part 71.73, "Packaging and Transportation of Radioactive Material", U.S. Nuclear Regulatory Commission, October 3, 2005.

[4] I-DEAS NX 12, 2006, UGS Corp.

[5] ABAQUS/Explicit Version 6.5-4, 2005, ABAQUS, Inc. [6] ASTM A240, 2002, "Standard Specification for

Chromium and Chromium-Nickel Stainless Steel Plate, Sheet, and Strip for Pressure Vessels and for General Applications" 